\title{
PATIENTS WITH EPILEPSY AS DRIVERS IN POLAND
}

\author{
Anna Staniszewska ${ }^{1}$, Agnieszka Mąka ${ }^{2}$, Urszula Religioni ${ }^{3}$, Dominik Olejniczak ${ }^{4}$, Grzegorz Juszczyk \\ Rafał Gierczyński ${ }^{5}$, Andrzej Marcinkiewicz ${ }^{6}$
}

${ }^{1}$ Medical University of Warsaw, Warsaw, Poland

Department of Experimental and Clinical Pharmacology

${ }^{2}$ Military Institute of Medicine, Warsaw, Poland

Registration

${ }^{3}$ Warsaw School of Economics, Warsaw, Poland

Collegium of Business Administration

${ }^{4}$ Medical University of Warsaw, Warsaw, Poland

Department of Public Health

${ }^{5}$ National Institute of Public Health - National Institute of Hygiene, Warsaw, Poland

Division of Epidemiological and Environmental Safety

${ }^{6}$ Nofer Institute of Occupational Medicine, Łódź, Poland

Department of Occupational Diseases and Environmental Health

\begin{abstract}
Background: Drivers suffering from epilepsy are commonly regarded as a threat to road safety. However, inability to use their own means of transport very often implies specific professional effects and lowers the quality of life. The aim of this study was to analyze the driving status of patients with epilepsy in Poland. Material and Methods: The prospective study was performed using an independent questionnaire developed by the authors, consisting of 4 parts: 1) socio-demographic information, 2) clinical information, 3) driving information, and 4) opinions about patients with epilepsy as drivers. The study was conducted in November 2018-September 2019. A total of 188 patients completed this study. Results: More than one-quarter of the patients have a driving license. Among them, 35 individuals (accounting for $18.62 \%$ of the whole study group) said that they had received their driving license after the diagnosis of epilepsy. In 10 cases $(5.32 \%)$, seizures occurred while the patients were driving and in 72 cases (38.30\%) while they were traveling as passengers. Among all socio-clinical factors, having a driving license was conditioned by the marital status $(\mathrm{p}=0.008)$ and education $(p=0.007)$. Other factors did not affect having a driving license or the time of obtaining the license ( $p>0.05$ for all cases). A relationship was observed between the occurrence of side effects of antiepileptic drugs and the occurrence of seizures while traveling as a car passenger $(p=0.001)$. Other factors did not affect the occurrence of epileptic seizures while traveling by car, either as a driver or a passenger $(\mathrm{p}>0.05)$. Conclusions: A significant proportion of the respondents were of the opinion that patients with epilepsy should not be allowed to obtain a driving license, which is probably related to concerns about the occurrence of epileptic seizures while driving. It is necessary to conduct a nationwide educational and information campaign on epilepsy in various aspects. Med Pr. 2021;72(4):341-50
\end{abstract}

Key words: drivers, accidents, consensus, driving regulations, driving license, epilepsy

Corresponding author: Anna Staniszewska, Medical University of Warsaw, Department of Experimental and Clinical Pharmacology, Banacha 1b, 02-097 Warsaw, Poland, e-mail: anna.staniszewska@wum.edu.pl

Received: October 26, 2020, accepted: February 8, 2021

\section{INTRODUCTION}

Patients with epilepsy are struggling with many problems and limitations, including being allowed to have a driving license. Unfortunately, for a long time there had been no legal regulations in this respect in Poland. It was only in 2011 that Annex No. 4b to the Regulation of the Minister of Health on medical examinations for drivers and persons applying for driving licenses solved the issues related to obtaining a driving license by patients with epilepsy in Poland [1]. After the law had changed, many patients lost their licenses, while other patients undergoing proper treatment gained a chance for being active drivers.

The minimum standards of physical and mental fitness for driving a power-driven vehicle, including those applicable to patients with epilepsy, are defined in Directive 2006/126/EC of the European Parliament and of the Council of 20 December 2006 on driving licenses [2]. Polish law based on this Directive stipulates that, during a medical examination, a person with epilepsy applying for a driving license of categories A, A1, A2, $\mathrm{AM}, \mathrm{B}, \mathrm{B} 1, \mathrm{BE}$ and $\mathrm{T}$ has to provide a health opinion issued by a neurologist. There are no contraindications 
to applying for a driving license if the patient on antiepileptic drugs (AEDs) has had no seizures in the past year, and provided that a medical check-up is carried out every half a year for a period of the next 2 years, and then every year for 3 consecutive years, and later depending on the neurologist's indications. An epileptic patient cannot drive a vehicle for half a year following the first day of the withdrawal of medications. After this time, the patient should undergo a check-up every 6 months for a period of 2 years, and then once a year for 3 consecutive years, and later depending on the neurologist's indications. If the patient requires a change of treatment, a neurologist determines the period of time during which the patient cannot drive vehicles [3].

The main aim of the study was to survey the driving status of patients with epilepsy in Poland. Specific objectives were:

to investigate the relationship between socio-demographic factors, clinical factors and a permission to drive vehicles;

to evaluate patients' opinions about epilepsy and driving.

\section{MATERIAL AND METHODS}

The prospective study was performed using an independent questionnaire developed by the authors. Most questions included in this survey were taken from surveys used in other studies devoted to the topic or were based on available scientific literature. The questionnaire consisted of 4 parts:

1) socio-demographic information (5 questions): age, gender, employment status, education, marital status;

2) clinical information (7 questions): duration of epilepsy, seizure type, number and kind of AEDs taken, AED side effects and AED dosage;

3) driving information (4 questions): Do you have a driving license? When did you get the driving license? Have you experienced a seizure while traveling as a passenger? Have you experienced a seizure while driving?

4. opinions about persons with epilepsy as drivers (6 questions): Should patients with epilepsy be allowed to have a driving license? How much time should pass since the last seizure for a person to be allowed to apply for a driving license? Does the type and frequency of seizures affect driving? Do people with epilepsy conceal the disease to get a driving license? Should a physician inform the driving license authority directly about the contraindications to driving? Can an epileptic patient be a professional driver?

All possible answers along with the questionnaire are shown in the Results section.

Patients were recruited to the study at the neurological clinic in Warsaw, Poland, in the period of November 2018-September 2019. A total of 204 patients with epilepsy filled in the questionnaire.

The inclusion criteria were as follows: persons over 18 years of age (legal age for driving in Poland) with the diagnosis of epilepsy; 16 respondents were excluded because they had not responded to all questions. A total of 188 patients completed the study.

The study was approved by the Ethics Committee of the Medical University of Warsaw, Poland (No. AKBE/159/16).) Participation in the survey was voluntary and anonymous. The completion of the survey meant that the patients gave their consent to participate in this study.

Statistical analyses were conducted using the following methods. A single factor analysis of variance (ANOVA) and the Kruskal-Wallis test were used for the purpose of statistical analysis of the results variance between the study groups (clinical and socio-demographic variables, and driving experience). The nonparametric Mann-Whitney $U$ test was applied for the comparison of differences between the 2 study groups. Statistica (10.0) software was used to perform all statistical analyses. The level of significance $(\mathrm{p}<0.05)$ was accepted as statistically reliable.

\section{RESULTS}

\section{Demographic and clinical data of the participants}

The study included 35 men and 153 women aged 18-58 years. The average age of the patients was $30.84 \pm 8.29$ years. Regarding the level of education, university education was prevalent $(\mathrm{N}=82,43.62 \%)$. The majority of the study participants were single persons $(\mathrm{N}=91,48.40 \%)$. Concerning their employment status, half of the patients $(\mathrm{N}=94,50 \%)$ were employed. The mean duration of epilepsy since the diagnosis was 165.81 months. The majority of the patients $(\mathrm{N}=75$, $39.89 \%$ ) did not know the type of seizure they had been diagnosed with. The treatment analysis revealed that an equal number of the respondents (about 47\%) were subject to monotherapy or polytherapy, and 5.85\% $(\mathrm{N}=11)$ were free of medication. Nearly half of the participants $(\mathrm{N}=87,46.28 \%)$ were treated with the new 
generation of AEDs and $87.77 \%(\mathrm{~N}=165)$ took medications more than twice/day. Side effects of AEDs were experienced by $44.15 \%(\mathrm{~N}=83)$ of the respondents. In the study, central nervous system symptoms were frequent side effects of AEDs ( $\mathrm{N}=53,28.19 \%)$. Patient characteristics are shown in Table 1.

More than a quarter $(\mathrm{N}=56,29.79 \%)$ of the patients had a driving license, and 35 of them (accounting for $18.62 \%$ of the whole study group) received a driving license after the diagnosis of epilepsy. In 10 cases $(5.32 \%)$, seizures occurred while the patients were driving, whereas 72 seizures $(38.30 \%)$ took place when the patients were traveling as passengers.

Less than half of the respondents $(\mathrm{N}=92,48.94 \%)$ were of the opinion that patients with epilepsy should be allowed to have a driving license. When asked how much time should pass from the last epileptic seizure for a person to be allowed to apply for a driving license, the largest number of respondents indicated 2 years $(\mathrm{N}=32,17.02 \%)$. The patients were also asked if the type and frequency of seizures affected driving in their opinion, and $76.60 \%$ of the sample $(\mathrm{N}=144)$ provided an affirmative answer. A comparable percentage of the respondents $(\mathrm{N}=145,77.13 \%)$ believed that patients with epilepsy conceal their illness when applying for a driving license. More than half of the patients $(\mathrm{N}=112,59.58 \%)$ were of the opinion that a physician should inform an appropriate driving license authority about the patient's illness. More than three-quarters of the patients $(\mathrm{N}=144,76.60 \%)$ believed that persons with epilepsy should not be professional drivers. Table 1 shows the driving characteristics of the patients.

While completing this survey, the participants to the study wrote their comments, which are presented below (the content of the comments remains unchanged; the patients have been numbered in order to ensure their anonymity):

Patient No. 1: "No offense to sick people, but even epileptics without seizures should not drive a car. Just like diabetics, they take medicines regularly, because they can never be sure that they won't have a seizure (so they have poor concentration), and they might bump into someone on the road. This is pretty much it. Honestly, they can have a driving license and kill themselves, but not a random pedestrian, especially a child or a mother with a baby."

Patient No. 2 (in response to Patient No. 1): "Everyone should live normally. If there have been no seizures for a few years and the EEG is correct, why should a patient lose the right to function normally? A healthy person can also have a seizure at any time. Any type. If so, let's deprive everybody of their driving licenses. Just in case."

Patient No. 3: "Current regulations make sense. They minimize the risk, but don't deprive patients of a chance for being able-bodied. Everyone can have a heart attack behind the wheel. However, in the case of an active epilepsy, a physician should directly inform the authorities about it."

Patient No. 4: "I agree with the opponents of issuing driving licenses to epileptics. We should care not only about our safety, but also about others."

Patient No. 5: "I'm against obtaining a driving license by a sick person. After 7 years free of seizures, I suddenly had one. And, for a moment, I had had an idea to get a driving license, not even to drive, but just in case."

Patient No. 6: "Maybe I'm too strict for other sick people, but I think it's good that I can't have a driving license. With age, you can understand it better. There are taxies and public transport anyway."

Patient No. 7: "I had a strong seizure on a bus, I smashed my head and leg, hard to think what could happen if I was driving a car."

Patient No. 8: "An epileptic patient should not sit behind the wheel. That's dangerous not only for the patient, but also for other road users."

\section{Results of statistical analysis}

Among all socio-clinical factors, having a driving license was conditioned by the marital status $(p=0.008)$ and education $(\mathrm{p}=0.007)$. The patients with epilepsy who had a driving license were most frequently married or those with higher education. The respondents with basic or vocational education usually did not have a driving license. Other factors did not affect having a driving license or the time of obtaining the license ( $p>0.05$ for all cases).

A relationship was observed between the occurrence of side effects of AEDs and the occurrence of seizures while traveling as a car passenger $(p=0.001)$. The patients reporting AED side effects experienced epileptic seizures while driving significantly more often.

Other factors did not affect the occurrence of epileptic seizures while traveling by car, either as a driver or a passenger $(\mathrm{p}>0.05)$.

\section{DISCUSSION}

\section{Driving license among epileptic patients}

Nowadays having a driving license is a very important aspect of everyday life. The ability to drive and having 
Table 1. Characteristics of the examined group with epilepsy from Poland in November 2018-December 2019

\begin{tabular}{|c|c|}
\hline Variable & $\begin{array}{c}\text { Participants } \\
(\mathrm{N}=188)\end{array}$ \\
\hline \multicolumn{2}{|l|}{ Demographic } \\
\hline \multicolumn{2}{|l|}{ age [years] } \\
\hline $\mathrm{M} \pm \mathrm{SD}$ & $30.84 \pm 8.29$ \\
\hline $\min .-\max$ & $18-58$ \\
\hline \multicolumn{2}{|l|}{ gender $[\mathrm{n}(\%)]$} \\
\hline female & $153(81.38)$ \\
\hline male & $35(18.62)$ \\
\hline \multicolumn{2}{|l|}{ education [n (\%)] } \\
\hline primary & $9(4.79)$ \\
\hline vocational & $20(10.64)$ \\
\hline secondary & $76(40.43)$ \\
\hline university & $82(43.62)$ \\
\hline \multicolumn{2}{|l|}{ marital status [n (\%)] } \\
\hline single & $91(48.40)$ \\
\hline married & $86(45.74)$ \\
\hline widowed & $9(4.79)$ \\
\hline divorced & $2(1.06)$ \\
\hline \multicolumn{2}{|l|}{ employment status [n (\%)] } \\
\hline unemployed & $32(17.02)$ \\
\hline employed & $94(50.00)$ \\
\hline student & $31(16.49)$ \\
\hline pension & $1(0.53)$ \\
\hline retired & $30(15.96)$ \\
\hline \multicolumn{2}{|l|}{ Clinical } \\
\hline \multicolumn{2}{|l|}{ duration of epilepsy [months] } \\
\hline $\mathrm{M} \pm \mathrm{SD}$ & $165.81 \pm 136.38$ \\
\hline $\min .-\max$ & $1-696$ \\
\hline \multicolumn{2}{|l|}{ type of seizure $[\mathrm{n}(\%)]$} \\
\hline primarily generalized & $33(17.55)$ \\
\hline partial & $31(16.49)$ \\
\hline secondarily generalized & $15(7.98)$ \\
\hline secondarily generalized + partial & $34(18.09)$ \\
\hline I don't know & $75(39.89)$ \\
\hline \multicolumn{2}{|l|}{ medication [n (\%)] } \\
\hline monotherapy & $88(46.81)$ \\
\hline polytherapy & $89(47.34)$ \\
\hline free of medication & $11(5.85)$ \\
\hline \multicolumn{2}{|l|}{ kind of AEDs* $[\mathrm{n}(\%)]$} \\
\hline old generation & $37(19.68)$ \\
\hline new generation & $87(46.28)$ \\
\hline old + new generation & $53(28.19)$ \\
\hline
\end{tabular}


Table 1. Characteristics of the examined group with epilepsy from Poland in November 2018-December 2019 - cont.

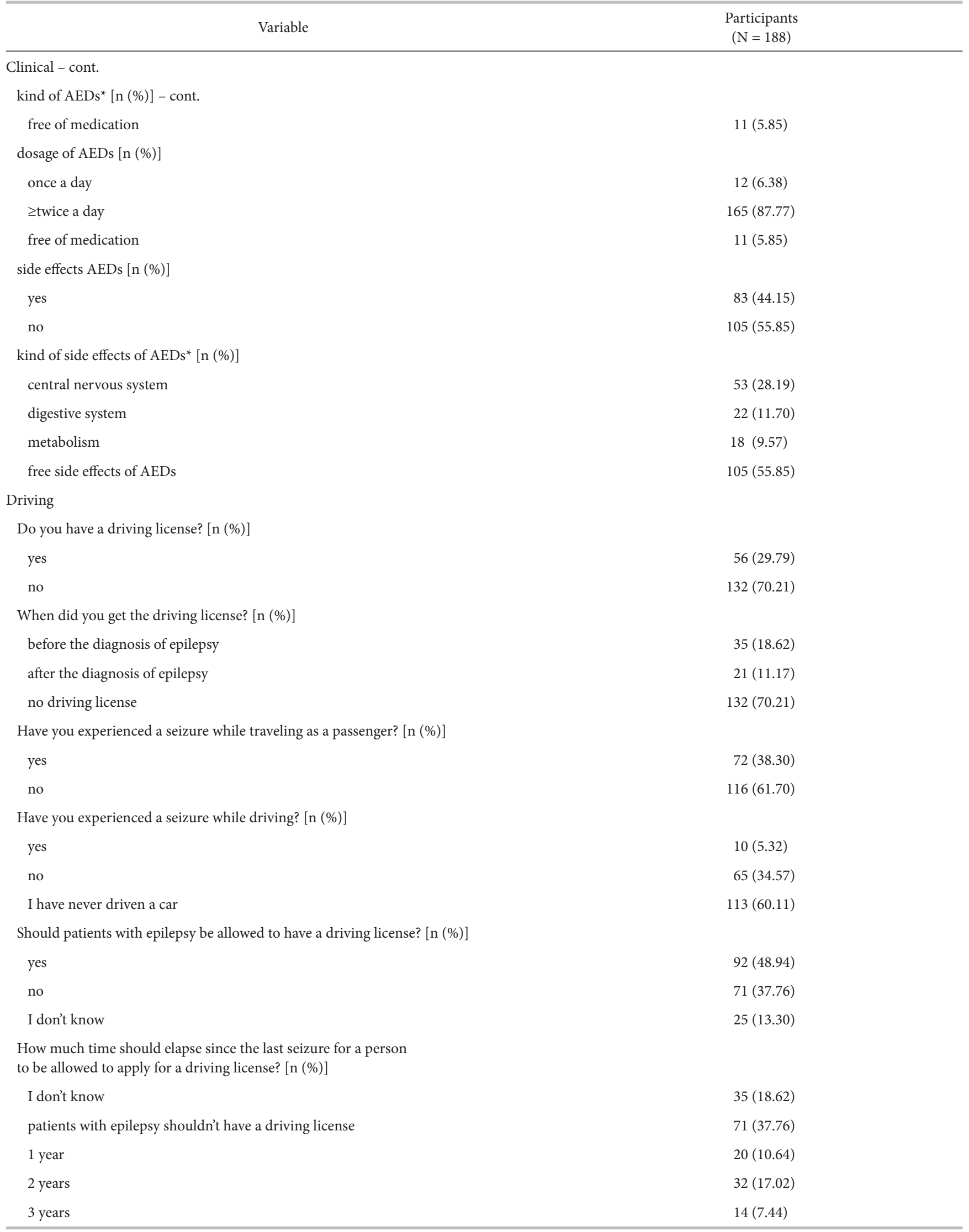


Table 1. Characteristics of the examined group with epilepsy from Poland in November 2018-December 2019 - cont.

\begin{tabular}{|c|c|c|}
\hline & Variable & $\begin{array}{l}\text { Participants } \\
(\mathrm{N}=188)\end{array}$ \\
\hline \multicolumn{3}{|l|}{ Driving - cont. } \\
\hline \multicolumn{3}{|c|}{$\begin{array}{l}\text { How much time should elapse since the last seizure for a person } \\
\text { to be allowed to apply for a driving license? [n (\%)] - cont. }\end{array}$} \\
\hline 4 years & & $3(1.60)$ \\
\hline 5 years & & $10(5.32)$ \\
\hline 10 years & & $3(1.60)$ \\
\hline \multicolumn{3}{|c|}{ Does the type and frequency of seizures influence driving? [n (\%)] } \\
\hline yes & & $144(76.60)$ \\
\hline no & & $19(10.10)$ \\
\hline I don't know & & $26(13.30)$ \\
\hline \multicolumn{3}{|c|}{ Do patients with epilepsy conceal their illness to obtain a driving license? [n (\%)] } \\
\hline yes & & $145(77.13)$ \\
\hline no & & $14(7.44)$ \\
\hline I don't know & & $29(15.43)$ \\
\hline \multicolumn{3}{|c|}{$\begin{array}{l}\text { Should a physician inform the driving license authority directly about the contraindica- } \\
\text { tions to driving? [n (\%)] }\end{array}$} \\
\hline yes & & $112(59.58)$ \\
\hline no & & $49(26.06)$ \\
\hline I don't know & & $26(14.36)$ \\
\hline \multicolumn{3}{|c|}{ Can an epileptic patient be a professional driver? [n (\%)] } \\
\hline yes & & $23(12.23)$ \\
\hline no & & $144(76.60)$ \\
\hline I don't know & & $21(11.17)$ \\
\hline
\end{tabular}

* Answers to the question on the kind of side effects of AEDs was given only by those respondents who declared the occurrence of any side effects of AEDs ( $\mathrm{N}=83$ ). The data did not yield a total of $100 \%$ because the respondents could choose multiple answers.

AEDs - antiepileptic drugs.

a driving license are especially important for patients with epilepsy.

Results of a study by Gilliam et al. [4] show that the possibility of having a driving license and being an active driver is a big issue for patients (64\%). Similar results were obtained in another study conducted on a group of 84 patients, which revealed that $64 \%$ of the respondents experienced a great dissatisfaction due to the inability to drive a car. It is worth noticing that, out of $25 \%$ of the patients who did not complain about not driving a car, $10 \%$ had a driving license and $15 \%$ did not [5]. Results of the Polish survey dated 2009 showed that every third respondent dreamed about obtaining a driving license in the future [6].

In this study, $29.79 \%$ of the patients had a driving license, and most of them had obtained it before they were diagnosed with epilepsy (18.62\%). These data are similar to the results obtained in a Polish study by PRO-EPI. In February and March 2009, the Pentor Research Institute conducted a survey on a representative sample of Poles $(\mathrm{N}=1042)$, among neurologists $(\mathrm{N}=179)$, adult patients with epilepsy $(\mathrm{N}=1019)$, parents of children with epilepsy $(\mathrm{N}=313)$, and principals of primary and junior high schools $(\mathrm{N}=200)$ [6]. The results of this study showed that $35 \%$ of adult Poles with epilepsy had a driving license, and $23 \%$ of them admitted to being active drivers. It should be emphasized that the study mentioned above had been conducted before the currently binding legal regulations were implemented in Poland.

The prevalence of driving licenses among patients with epilepsy was relatively high in this study compared with the results obtained in West China (26.8\% individuals reported that they had had a driving license at some 
point, and $26.5 \%$ indicated that they had a currently valid license; $46.6 \%$ of the latter group obtained a driving license after the disease onset) [7], which is a similar result to the one reported in the USA (31.3\%) [8], but relatively low compared to the results obtained in Japan (38.9\%) [9], and the Republic of Korea (40\%) [10]. Differences between particular results might be due to the fact that individual countries have different legal restrictions, studies were carried out in different time periods, either before or after the introduction of regulations, and the populations examined varied in numbers. However, it can be generally concluded that the results presented above are confirmed by the results of a study carried out in 7 European countries, where the percentage of people with epilepsy who had a driving license was significantly lower (44\%) than that of the general population $(67 \%)$ [11].

For some time, Belgian law required a 2-year seizure-free period to allow an epileptic patient to apply for a driving license. A group of neuroscientists estimated that $70 \%$ of the patients with epilepsy who were not allowed to drive after the first epileptic seizure continued to drive. In addition, one-third of them did it regularly. Interestingly, almost half of the respondents believed that it should be allowed for epileptic patients to drive despite the frequent occurrence of epileptic seizures. Many patients did not report seizures to doctors [12].

In this study, $38.30 \%$ of the respondents experienced a seizure while traveling as passengers. A vast majority of the epileptic patients $(60.11 \%)$ declared that they did not drive vehicles, while $5.32 \%$ of those who had a driving license experienced a seizure while driving. This coincides with the employment status, since 50\% of those affected were employed, which shows that having a driving license and being employed often go hand in hand.

An EU directive stipulates that persons with epilepsy can apply for a car or motorcycle driving license if they have had no disease symptoms for 1 year [2]. Similarly, in Poland, one can apply for a driving license if there have been no seizures for 1 year [3]. Despite the currently binding regulation, only $17.02 \%$ of the respondents indicated a correct answer when asked how much time should elapse since the last seizure for a person to be allowed to drive again. This shows that patients' knowledge is insufficient and/or neurologists do not provide patients with accurate information on the currently binding law.

In this study, most of the respondents indicated that many patients (77.13\%) who want to obtain a driving license conceal the disease. The majority of the respondents $(59.58 \%)$ were aware of the overall impact of the disease on driving motor vehicles and knew that a physician is required to notify relevant authorities of the disease. After the change in regulations, it is now the patients with epilepsy who should be aware of their legal obligation to re-assess their health condition in order to determine the existence or absence of health contraindications to driving in the event of epilepsy or seizures [3]. Therefore, special attention should be paid to educating patients both by neurologists, medical examiners, as well as mass media or social media, and other websites dedicated to patients with epilepsy.

\section{Relationship between seizures and accidents}

Drivers with epilepsy are commonly perceived as a threat to traffic safety. Having analyzed car accidents, Sheth et al. [13] stated that although an average of 44027 U.S. drivers died annually as a result of motor vehicle crashes in 1995-1997, only 86 deaths listed in mortality reports $(0.2 \%$, a range of $82-97)$ were associated with seizures. "The incidence rate of fatal crashes in patients with seizures was 2.3 times higher than the rate in patients with cardiovascular and hypertensive diseases, and 4.6 times higher than the rate in patients with diabetes. The proportionate mortality ratio for motor vehicle crashes in patients with seizures was low (0.2); most patients with epilepsy died of common cardiovascular and systemic disorders" [13]. Alcohol caused 156 times more driver deaths than seizures. Young drivers (aged 1624 years) died in accidents 123 times more often than drivers of any age who caused car crashes due to a seizure. The driver fatality crash rate for the general population was 2.6 times higher than the epilepsy-related driver fatality crash rate. This is because seizures are rarely a cause of crashes, as opposed to alcohol abuse, driver errors, or road conditions [13].

An analysis of statistical data presented in the 2005 EU Report ("A report of the Second European Working Group on Epilepsy and Driving, an advisory board to the Driving Licence Committee of the European Union. Final report; 3 April 2005: Epilepsy and Driving in Europe") shows that the effect of epilepsy on the risk of accidents is rather small, when considering the fact that the percentage of patients with epilepsy in the general adult population is around $0.6 \%$, and approx. $50 \%$ of the group have a driving license. Thus, it is estimated that adult epileptic drivers constitute only $0.3 \%$ of the total population. On the basis of an analysis of statistical data, it can be concluded that the impact of patients with 
epilepsy on road safety in Europe is very small and it can be estimated at about $0.25 \%$ of all road accidents [14]. In Australia, epilepsy caused only 9-19 traffic accidents in 1991, thus being the cause of $0.025-0.053 \%$ of all traffic accidents in that year [15].

"General statistics on car accidents involving persons with epilepsy show an increased risk, although it is still lower $(0.1-0.3 \%)$ than the risk associated with alcohol (6-9\%)" [16]. A retrospective study conducted in the United Kingdom [17] estimated the risk of vehicular accidents over a period of 3 years in a group of drivers with a history of either single seizures or epilepsy $(\mathrm{N}=16958)$, and compared it with the risk in a cohort of drivers $(\mathrm{N}=8888)$. After adjustment for the differences between the 2 populations regarding age, sex, driving experience and mileage, no evidence was found for any overall increase in the risk of accidents in the population of drivers with a history of epilepsy. "Although no overall differences in the total road traffic accident rates were observed, the rate of serious injuries was $40 \%$ higher in the epilepsy cohort, and there was evidence of a 2-fold increase in the non-driver fatalities."

According to the article by Wada [18], the accident rate due to seizures was 0.7 per 100 license holders per year. However, Yamahana et al. [19] reported that 9.7\% of patients with epilepsy had traffic accidents in a 3-year observation period, but only $1.6 \%$ were seizure-related.

\section{Other clinical aspects}

Special attention should be paid to the impact of AEDs on the patient's ability to operate mechanical appliances. In the course of treatment with AEDs, side effects related to the nervous system can occur, such as dizziness, drowsiness, or the prolongation of reaction time to a degree that prevents driving, operating machinery and devices in motion.

The effect of surgical treatment of epilepsy, including possible deficits, on the ability to operate mechanical devices should also be considered. This issue refers especially to the temporal lobe and problems related to the field of vision and the frequency of epileptic seizures. However, there are few publications in this area. In a study on a group of 24 patients, 6 of them $(25 \%$ according to the Esterman test), or 10 of them ( $42 \%$ according to the Goldmann test), showed no postoperative effects associated with a significant limitation of the field of vision [20]. No seizures, according to the Engel classification (Engel class 1), were observed in 7 out of 13 patients who had had anterior temporal lobectomy, whereas 3 patients (23\%) experienced $<2$ seizures/year
(Engel class 2) and 3 patients (23\%) showed a $>90 \%$ improvement in the frequency of seizures (Engel class 3 ). Although 7 patients (54\%) passed the visual field test and 7 patients (54\%) were seizure-free, only 5 of the 7 seizure-free patients (i.e., $38 \%$ of the total number of patients) represented visual fields that would make them eligible to drive [21].

\section{Opinions about drivers with epilepsy}

Driving license is useful not only for touristic and professional purposes, but also for looking for a job, as today having a car can facilitate many everyday activities. Disqualification of patients due to epilepsy increases their "social disability." In this study, however, the majority of patients agree with the current law, when asked about driving vehicles professionally. The vast majority (76.60\%) stated that patients with epilepsy should not be professional drivers. A small percentage (12.23\%) was of a different opinion or claimed that they had no opinion in this regard (11.17\%).

Public opinion about allowing persons with epilepsy to obtain a driving license is rather negative. Almost half of the Poles surveyed (49\%) believe that patients should not be allowed to obtain a driving license. However, specialists express more positive opinions: more than two-thirds of neuroscientists were of the opinion that some patients should be given a chance to obtain a conditional driving license [6].

The examples presented above show that opinions seem to be split on whether patients with epilepsy should be allowed to have a driving license or not, even among representatives of the patient group concerned. The comments presented in the Results section above indicate that patients with epilepsy are of the opinion that they should not be allowed to drive a car. In this study, 37.76\% of the respondents stated that patients with epilepsy should not be allowed to have a driving license. This is contradictory to the results of the studies mentioned earlier in this paper, which showed that the majority of patients with epilepsy felt a great dissatisfaction with not being able to drive a car [4-6]. The most concerned group, that is the patients themselves, felt anxiety even if they would like to be allowed to drive a car because they knew that epilepsy is an unpredictable disease and seizures may occur in the least expected time and place.

The main reason for the negative attitude of society towards epileptic patients having a driving license is probably ignorance about the disease, its treatment and the control of epileptic seizures. The families of persons with epilepsy probably do not approve of their ill family 
members taking driving examinations and driving a car because of fear and overprotection; however, this issue should be investigated in further detail.

\section{CONCLUSIONS}

For some time the diagnosis of epilepsy was an obstacle to being an active driver in Poland. Currently, this issue is regulated by law. Results of this study showed that almost one-third of patients with epilepsy had a driving license, and a small proportion of them obtained the license after the diagnosis of epilepsy. Having a driving license was the most common in married persons and those with higher education. Patients suffering from AED side effects much more frequently indicated experiencing a seizure while driving.

A significant proportion of the respondents were of the opinion that patients with epilepsy should not be allowed to obtain a driving license, which is probably related to concerns about the occurrence of epileptic seizures while driving. It is necessary to conduct a nationwide educational and information campaign on epilepsy and the possibility of becoming an active driver among patients with epilepsy. These actions will pick up the level of the quality of life, and may also help decrease the amount of stigma experienced by patients with epilepsy.

Physicians who judge the possibility of driving should pay special attention to educating epileptic patients. On the one hand, they should inform them in detail about the factors influencing the increased risk of an epileptic seizure while driving, and, on the other hand, about the patient's legal obligations: if the patient has had a seizure, he or she should stop driving a car and report this fact to the relevant authority. The patient should also discuss seizures honestly with his or her physician and work with them to find appropriate treatment.

To the best of the authors' knowledge, this is the first published study about driving licenses among Polish patients with epilepsy. Hence, it should constitute a foundation for further and more detailed research.

\section{REFERENCES}

1. [Regulation of the Minister of Health of 15 April 2011 amending the regulation on medical examinations of drivers and applicants for the right to drive vehicles. J Laws 2011, item 503]. Polish.

2. [Directive 2006/126/EC of the European Parliament and of the Council of 20 December 2006 on driving licences]. Polish.
3. [Regulation of the Minister of Health of 29 August 2019 on medical examinations of people applying for the authorization to drive vehicles and drivers. J Laws 2019, item 1659]. Polish.

4. Gilliam F, Kuzniecky R, Faught E, Czarny L, Stolarz G, Schrodt R. Patient validated content of epilepsy-specific quality of life measurement. Epilepsia. 1997;38(2):233-6, https://doi.org/10.1111/j.1528-1157.1997.tb01102.x.

5. Staniszewska A, Tarchalska-Kryńska B. Czego obawiają się chorzy na padaczkę? Probl Ter Monit. 2008;3:193-202.

6. PRO-EPI - Understanding epilepsy at work. In: Press Centre PAP. Congress and Conference Proceedings; 2009 Sep 16; Warsaw, Poland. Unpublished materials.

7. Chen J, Yana B, Lu H, Ren J, Zou X, Xiao F, et al. Driving among patients with epilepsy in West China. Epilepsy Behav. 2014;33:1-6, https://doi.org/10.1016/j.yebeh.2014. 01.020 .

8. Berg AT, Vickrey BG, Sperling MR, Langfitt JT, Bazil CW, Shinnar S, et al. Driving in adults with refractory localization-related epilepsy. Neurology. 2000;54(3):625-30, https://doi.org/10.1212/wnl.54.3.625.

9. Takeda A, Kawai I, Fukushima Y, Yagi K, Seino M. Epilepsy and driving in Japan, current status as investigated in a prospective survey. J Epilepsy. 1992;5(2):135-9, https://doi.org/10.1016/S0896-6974(05)80061-1.

10. No YJ, Lee SJ, Park HK, Lee SA. Factors contributing to driving by people with uncontrolled seizures. Seizure. 2011;20(6):491-3, https://doi.org/10.1016/j.seizure.2011. 02.001 .

11. Social aspects of epilepsy in the adult in seven European countries. The RESt-1 Group. Epilepsia. 2000;41(8):998-1004, https://doi.org/10.1111/j.1528-1157.2000.tb00285.x.

12. Schmedding E. Personal inquiry in a group of 70 Belgian neurologists. Chantilly: 1996.

13. Sheth SG, Krauss G, Krumholz A, Li G. Mortality in epilepsy, driving fatalities vs other causes of death in patients with epilepsy. Neurology. 2004;63(6):1002-7, https://doi. org/10.1212/01.WNL.0000138590.00074.9A.

14. European Commission [Internet]. The Commission [cited 2019 Dec 15]. Epilepsy and Driving in Europe. A report of the Second European Working Group on Epilepsy and Driving, an advisory board to the Driving Licence Committee of the European Union. Final report, 3 April 2005, Epilepsy and Driving in Europe Available from: https://ec.europa.eu/transport/road_safety/sites/roadsafety/files/pdf/behavior/epilepsy_and_driving_in_europe_final_report_v2_en.pdf.

15. Black AB, Lai NY. Epilepsy and driving in South Australia - an assessment of compulsory notification. Med Law. 1997;16(2):253-67. 
16. Cross JH. Epilepsy in the Who European region, fostering epilepsy care in Europe. Epilepsia. 2011;52(1):187-8, https://doi.org/10.1111/j.1528-1167.2010.02903.x.

17. Taylor J, Chadwick D, Johnson T. Risk of accidents in drivers with epilepsy. J Neurol Neurosurg Psychiatry. 1996;60(6):621-7, https://doi.org/10.1136/jnnp.60.6.621.

18. Wada T. Issues on epilepsy and driving. Psychiatry. 1967;9:429-37.

19. Yamahana Y, Kudo N. Socio-medical aspect of epilepsy, traffic problems. Clin Psychiatry. 1972;1:368-79.
20. Manji H, Plant GT. Epilepsy surgery, visual fields, and driving, a study of the visual field criteria for driving in patients after temporal lobe epilepsy surgery with a comparison of Goldmann and Esterman perimetry. J Neurol Neurosurg Psychiatry. 2000;68(1):80-2, https://doi.org/ 10.1136/jnnp.68.1.80.

21. Ray A, Pathak-Ray V, Walters R, Hatfield R. Driving after epilepsy surgery, effects of visual field defects and epilepsy control. Br J Neurosurg. 2002;16(5):456-60, https://doi. org/10.1080/0268869021000030258. 